\title{
Health effects among refrigeration repair workers exposed to fluorocarbons
}

\author{
DD CAMPBELL, JE LOCKEY, J PETAJAN, BJ GUNTER, AND WN ROM
}

\author{
From the Departments of Internal Medicine, Family and Community Medicine, and Neurology, Rocky \\ Mountain Center for Occupational and Environmental Health, University of Utah School of Medicine, Salt \\ Lake City, Utah 84112, USA
}

ABSTRACT Refrigeration repair workers may be intermittently exposed to fluorocarbons and their thermal decomposition products. A case of peripheral neuropathy (distal axonopathy) in a commercial refrigeration repairman prompted an epidemiological investigation of the health of refrigeration repair workers. No additional cases of peripheral neuropathy were identified among the 27 refrigeration repair workers studied. A reference group of 14 non-refrigeration repair workers was also studied. No differences were noted between groups for the ulnar (motor and sensory), median (motor and sensory), peroneal, sural, or tibial nerve conduction velocities. Refrigeration repair workers reported palpitations and lightheadedness significantly more often than workers in the reference group. No clinical neurological or electroneurophysiological abnormalities were detected in eight refrigeration repair workers followed up for three years during continuous employment.

Fluorocarbons are used in industry as refrigerants, solvents, and propellants. In the refrigeration industry three widely used fluorocarbons are dichlorodifluoromethane (Fluorocarbon 12, FC 12), monochlorodifluoromethane (Fluorocarbon 22, FC 22), and chloropentafluoroethane (Fluorocarbon 115, FC 115); the current threshold limit value for each is 1000 ppm. ${ }^{1}$ Refrigeration repair workers may be exposed to fluorocarbons during repairs of leaks or while changing a system. Contact with an open flame or hot metal, which may occur during repair of leaks, results in thermal decomposition producing hydrogen chloride, hydrogen fluoride, phosgene, carbon dioxide, and chlorine. Cadmium is a component of the solder often used in construction and repair in the refrigeration trade and may also represent an occupational hazard.

Although several aliphatic hydrocarbons are known to produce peripheral neuropathy, ${ }^{23}$ there are no reported studies to determine the neurotoxic potential of fluorocarbons and their thermal decomposition products. Cadmium chloride has been shown to produce peripheral nerve injury in laboratory animals, but there have been no human studies. ${ }^{4}$

The toxicity of fluorocarbons was evaluated in the 1960s because of an increase in deaths from asthma

Accepted 1 July 1985 associated with the increase in the use of hand held bronchodilator nebulisers containing fluorocarbons as propellants. ${ }^{56}$ In the United States sudden unexplained deaths in aerosol "sniffers" have been reported. Investigators believe that this may be due to cardiac arrhythmias induced by the fluorocarbon propellants contained in many commercially available aerosols. ${ }^{7}$ Reinhardt et al showed that fluorocarbons could sensitise the canine myocardium to adrenaline, resulting in serious cardiac arrhythmias. ${ }^{8}$ Speizer et al reported that pathology personnel exposed to FC 22 and FC 12 while preparing frozen sections had a greater prevalence of palpitations than an unexposed control group 9 ; concentrations of FC 22 averaged $300 \mathrm{ppm}(0 \cdot 03 \%)$. Continuous electrocardiographic monitoring of several exposed subjects in the course of their work showed multiple arrhythmias.

In 1978 a local refrigeration repairman developed a progressive sensorimotor peripheral neuropathy. After admittance to hospital and extensive evaluation, the aetiology could not be determined. A preliminary electroneurophysiological study of ten of his coworkers on the left median sensory, left ulnar sensory, and left sural nerves showed mild abnormalities in seven which suggested a possible link with workplace exposures. In the present study the potential adverse health effects of refrigeration repair work were evaluated with particular reference to neurological, cardiovascular, and respiratory abnormalities. 


\section{Methods}

\section{STUDY SUBJECTS}

A group of 29 white, male refrigeration repair workers were identified for inclusion in the study. Twenty four were employed at the time of the study in the company for whom the referral case had worked. Five other refrigeration repair workers who had been part of the preliminary study in 1979 were also included. Of this group of 29, 27 participated, including eight from the original study. Of the original ten, one had moved out of state whereas one other refused to participate but was still employed as a refrigeration worker and apparently healthy. The referral case was also examined and his results are presented separately.

A reference group was selected to compare results of the medical questionnaire and the electroneurophysiological studies. The reference subjects were selected from one of two local unions of plumbers and pipe fitters or insulation workers. Potential reference subjects were randomly selected from five year age groups to match the age distribution of the study subjects. Potential reference subjects were excluded if they had prior neurological impairment, a history of low back injury, or if they had been exposed to fluorocarbons within the previous 12 months. A total of 32 white, male, non-refrigeration repair workers were contacted. Seven declined to participate, six had a history of prior back injury, sciatic neuropathy, or other neurological problems, and three had worked in the refrigeration trade within the past 12 months. This left 16 potential unexposed subjects of whom 14 participated. This number of reference subjects resulted in an $80 \%$ power to detect a difference of 3 metres per second in nerve conduction velocities with alpha set at $5 \%$ for a two tailed $t$ test.

\section{MEDICAL LABORATORY TESTING}

Medical history, physical examinations, and testing were performed by physicians at the University of Utah Medical Center at least 16 hours after the last work exposure. A questionnaire was administered to determine the presence of symptoms related to the neurological, cardiovascular, and respiratory systems. Chronological occupational histories and information on alcohol consumption were obtained from each study subject. Respiratory function was assessed with the forced vital capacity manoeuvre. The forced vital capacity (FVC) and forced expiratory volume in one second $\left(F_{E V}\right)$ were obtained according to the American Thoracic Society standards using an Ohio-Med 822 rolling dry seal spirometer and a Spirotech microprocessor. ${ }^{10}$ The forced expiratory manoeuvre was repeated until at least two tests were within $5 \%$ of each other and within $5 \%$ of the best test-that is, at least three acceptable tests. All the results were cor- rected to standard pressure and body temperature. $\overline{\bar{\alpha}}$ The best FVC and $\mathrm{FEV}_{1}$ were used for interpretation $\bar{Z}$

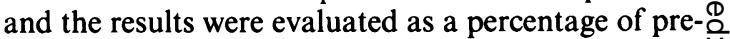
dicted normals as measured by Knudson et al. ${ }^{11}$ Chest radiographs and standard 12-lead electrocardiograms $\stackrel{\oplus}{\rightarrow}$ at rest were obtained. Blood was analysed for com-으 plete blood counts with differential, albumin, totalo protein, glucose, calcium, phosphorus, uric acid, urea $\frac{\bar{\sigma}}{\widehat{\sigma}}$ nitrogen, creatinine, lactic dehydrogenase, alkaline $\stackrel{\mathbb{Q}}{\mathbb{Q}}$ phosphatase, serum aspartate and alanine aminotransferase, bilirubin, triglycerides, cholesterol, elec- trolytes, and zinc protoporphyrin. Routine urine. analysis was performed. Reference subjects received $\overrightarrow{\vec{\omega}}$ an identical evaluation and tests except for pulmonaryo function tests, electrocardiograms, and chest radio-요 graphs.

ELECTRONEUROPHYSIOLOGICAL TESTING Nerve conduction speeds were determined at room $\vec{\circ}$ temperature on a TE 42 Electromyograph using sur- $-\checkmark$ face electrodes on all study and reference subjects. The음 following nerves were tested bilaterally using supra- $-\overrightarrow{-}$ maximal stimuli: ulnar motor, ulnar sensory, median $\mathbb{Q}^{\top}$ motor, median sensory, tibial, peroneal, and sural. All nerve conduction velocities were measured orthodromically, except the sural nerve, which was measured antidromically. Distal latencies were measured $\overrightarrow{0}$ on the median and ulnar motor, peroneal, and tibal nerves. Sensory action potentials were measured the ulnar sensory, median sensory, and sural nerve. Skin temperature was greater than $30^{\circ} \mathrm{C}$ at the site:of recording for all tests.

\section{Results}

\section{CASE REPORT}

The referral case was a 33 year old white man who entered the refrigeration repair trade in 1971 . In 1976 he began to notice loss of weight, difficulty in concen-疋 tration, depression, and weakness. In the summer of 1978 , while repairing a leak in a refrigeration system, $\frac{\sigma}{3}$ the pipe broke releasing fluorocarbons into the work. area. He became nauseated, vomited, and complained of generalised weakness and abdominal cramps. $\mathrm{He}^{3}$ left work and remained off work for several weeks. In음 July 1978 his nerve conduction velocities in his left legp were as follows: peroneal nerve, $40 \mathrm{~m} / \mathrm{sec}$ (normaE. $>40 \mathrm{~m} / \mathrm{sec}$ ); tibial nerve, $23 \mathrm{~m} / \mathrm{sec}$ (normah $>35 \mathrm{~m} / \mathrm{sec}$ ); and sural nerve $21 \mathrm{~m} / \mathrm{sec}$ (normaf $>37.5 \mathrm{~m} / \mathrm{sec}$ ).

In October 1978 he was admitted to hospital forw further evaluation of his distal axonopathy. On phys-ర్ర ical examination decreased vibratory and positiono senses in the toes were noted; touch sensation wast intact. His muscle strength, bulk, and tone were normal. Deep tendon reflexes were mildly decreased in 
the biceps and triceps bilaterally. The remainder of the examination gave normal results. Laboratory evaluation showed no abnormalities in albumin, liver enzymes, bilirubin, glucose tolerance, vitamin $\mathbf{B}_{12}$, folate, sedimentation rate, urine analysis, cerebrospinal fluid, chest radiograph, or thyroid function. Serological test results for rheumatoid arthritis and syphilis were negative. Urinary lead and mercury concentrations were well below the accepted normal level. The aetiology for his distal axonopathy could not be determined, but the history suggested a possible link with exposure at work. He returned to refrigeration repair work for 11 months and was re-examined in 1981 with the other refrigeration repair workers in this study. At that time his physical condition was unchanged, with persistent sensory deficits in the feet and hands. The nerve conduction velocities had considerably improved: left peroneal nerve, $46.5 \mathrm{~m} / \mathrm{sec}$; left tibial nerve $45.6 \mathrm{~m} / \mathrm{sec}$; and left sural nerve, $34.9 \mathrm{~m} / \mathrm{sec}$.

\section{STUDY FINDINGS}

Among the 27 refrigeration repair workers studied, no additional cases of peripheral neuropathy were identified and the chest radiographs, pulmonary function tests, electrocardiograms, and blood and urine test results were all within normal limits.

The mean age of the 27 refrigeration repair workers was 32 and of the 14 reference subjects, 35 . The mean number of symptoms (out of 34) among the exposed was 5.8 compared with $4 \cdot 1$ in the reference group. There were similar numbers of drinkers, ex-drinkers, and non-drinkers of alcohol in the two groups.

Table 1 shows the 11 most common symptoms and the frequency of responses for both the refrigeration repair and reference workers. Lightheadedness was reported by 18 workers (67\%); tiring easily by 12 $(44 \%)$; and breathing trouble, headaches, and pressure in the chest were each reported by nine workers $(33 \%)$. Seven workers $(26 \%)$ reported palpitations, numbness in fingers, irritability, or trouble remem- bering. Perspiring easily and eye irritation were each reported by six workers $(22 \%)$. Two symptoms, lightheadedness and palpitations, were reported significantly more often by the refrigeration repair workers. Twelve of the 18 workers reporting lightheadedness named fluorocarbons as the cause and four of nine experiencing trouble breathing named soldering or welding. Other reported symptoms were not so closely associated with particular workplace exposures.

Table 2 shows the mean nerve conduction velocities and the lower limits of normal. The mean nerve conduction velocities of the refrigeration repair workers were standardised to the age distribution of the reference group. The refrigeration repair workers had mean nerve conduction velocities essentially the same as the unexposed reference group for all nerves studied. Sural nerve conduction velocities for both groups were, on average, at the lower limits of normal. Sensory action potentials of the ulnar and median sensory and the sural nerves were normal, as were distal latencies of the tibial, peroneal, median motor, and ulnar motor nerves.

Table 3 shows the average nerve conduction velocities of eight workers followed up from 1978 to 1981 . The average nerve conduction velocities for the ulnar and median sensory nerves increased during this period. No change in working conditions could account for this increase and the differences were not large by comparison with the measurement variability.

\section{Discussion}

This cross sectional study showed a significant increase in lightheadedness and palpitations in refrigeration repair workers intermittently exposed to fluorocarbons compared with a reference group of unexposed workers. No objective evidence of peripheral nerve dysfunction was found in the refrigeration repair workers and no decrement in nerve conduction

Table 1 Symptoms reported by refrigeration workers and an unexposed (reference) group of workers

\begin{tabular}{|c|c|c|c|c|}
\hline \multirow[t]{2}{*}{ Symptom } & \multicolumn{2}{|c|}{ Refrigeration workers $(n=27)$} & \multicolumn{2}{|c|}{ Reference workers $(n=14)$} \\
\hline & $N o$ & $\%$ & $N o$ & $\%$ \\
\hline $\begin{array}{l}\text { Lightheadedness* } \\
\text { Tires easily } \\
\text { Pressure in the chest } \\
\text { Trouble breathing } \\
\text { Headaches } \\
\text { Palpitations* } \\
\text { Numbness in fingers } \\
\text { Irritability } \\
\text { Trouble remembering } \\
\text { Perspiring easily } \\
\text { Eye irritation }\end{array}$ & $\begin{array}{r}18 \\
12 \\
9 \\
9 \\
9 \\
7 \\
7 \\
7 \\
7 \\
6 \\
6\end{array}$ & $\begin{array}{l}67 \\
44 \\
33 \\
33 \\
33 \\
26 \\
26 \\
26 \\
26 \\
22 \\
22\end{array}$ & $\begin{array}{l}3 \\
3 \\
2 \\
4 \\
7 \\
0 \\
1 \\
1 \\
1 \\
4 \\
7\end{array}$ & $\begin{array}{r}21 \\
21 \\
14 \\
28 \\
50 \\
0 \\
7 \\
7 \\
7 \\
28 \\
50\end{array}$ \\
\hline
\end{tabular}

* $p<0.05$ by Fisher's exact test, two tailed. 
Table 2 Average maximal nerve conduction velocities of refrigeration repair workers and a reference group of unexposed workers*

\begin{tabular}{|c|c|c|c|c|}
\hline \multirow[t]{2}{*}{ Nerve (lower limit of normal) } & \multicolumn{2}{|c|}{ Refrigeration workers $* *(n=27)$} & \multicolumn{2}{|c|}{ Reference workers $(n=14)$} \\
\hline & Mean & $S D^{* * *}$ & Mean & $S D^{* * *}$ \\
\hline $\begin{array}{l}\text { Ulnar motor }(48) \\
\text { Ulnar sensory (37) } \\
\text { Median motor (48) } \\
\text { Median sensory (37) } \\
\text { Peroneal }(40) \\
\text { Sural }(37 \cdot 5) \\
\text { Tibial (35) }\end{array}$ & $\begin{array}{l}60 \\
42 \\
60 \\
42 \\
49 \\
37 \\
48\end{array}$ & $\begin{array}{l}4 \cdot 0 \\
3 \cdot 6 \\
4 \cdot 8 \\
3 \cdot 8 \\
3 \cdot 2 \\
3 \cdot 9 \\
6 \cdot 3\end{array}$ & $\begin{array}{l}60 \\
41 \\
60 \\
42 \\
47 \\
37 \\
49\end{array}$ & $\begin{array}{l}4 \cdot 1 \\
5 \cdot 2 \\
3 \cdot 6 \\
4 \cdot 2 \\
3 \cdot 7 \\
4 \cdot 0 \\
5 \cdot 3\end{array}$ \\
\hline
\end{tabular}

*All values are in metres per second.

**Nerve conduction velocity averages are standardised to the age distribution of the reference group.

*** Standard deviation.

$p>0.05$ for all tests of differences between means.

velocities was found in eight refrigeration repair workers followed up over three years of continuous employment.

Personal air samples were obtained from two refrigeration repair workers who participated in the study over the course of a typical work shift. Levels for FC 22 and FC 115 were found to be $1.4 \mathrm{ppm}$ and $2.2 \mathrm{ppm}$, respectively. These levels are well within the threshold limit value of $1000 \mathrm{ppm}$. No symptoms were reported during this work shift, which included repairing leaks from pipes containing fluorocarbons.

Speizer et al found arrhythmias among workers who had reported a high frequency of palpitations and who were exposed to fluorocarbons at levels of FC 22 averaging 300 ppm. ${ }^{9}$ Nevertheless, experimental human exposure to fluorocarbons under controlled conditions with electrocardiographic monitoring have failed to show significant abnormalities. Azar et al exposed volunteers to 10000 ppm FC 12 for 2.5 hours and found no untoward reactions or cardiac arrhythmias. ${ }^{12}$ Stewart et al exposed volunteers to 1000 ppm FC 12 for eight hours a day, five days a week, for four weeks. ${ }^{13}$ No untoward effects, electroencephalographical abnormalities, or cardiac arrhythmias were shown. No such studies have been reported for FC 22 or FC 115.

Lightheadedness and palpitations are difficult symptoms to evaluate, as they are often found in people with no underlying pathology. On the other hand, these symptoms are frequently associated with various cardiac arrhythmias including ventricular tachy-

Table 3 Average nerve conduction velocities (metres/second) among eight refrigeration repair workers followed up from 1978 to 1981

\begin{tabular}{lll}
\hline Nerve & 1978 & 1981 \\
\hline Left ulnar sensory & 38 & 43 \\
Left median sensory & 36 & 40 \\
Left sural & 36 & 36 \\
\hline
\end{tabular}

$p>0.05$ for all tests of differences between means. cardia. ${ }^{14}$ Lightheadedness may also represent a direct $\stackrel{\mathbb{D}}{3}$ effect on the central nervous system. In the light of our findings and those of Speizer et $\mathrm{l}^{9}$ further evaluation $\tilde{\mathrm{N}}$ of these symptoms in refrigeration repair workers using continuous ambulatory electrocardiographic monitoring appears to be indicated.

No association was found between refrigeration repair work and peripheral neuropathy. Some poten-T tial sources of bias may contribute towards finding no음 association between exposure and disease in occupational studies. One important potential source of bias is the "healthy worker effect." 15 We can dis- $\vec{\varphi}$ count this effect in the present study in three was.o Firstly, early in the course of distal axonopathy individual may experience few or no symptoms a do it would, therefore, be an unlikely cause for that individual to leave his place of employment. Secondly, a reference group of workers was used to compare $\frac{\partial}{D}$ results of electroneurophysiological testing, rather than the general population norms. And, finally, eight $\overrightarrow{\vec{O}}$ workers were followed up for three years and were 3 found to have no deterioration in their electroneurophysiological tests.

Another potential source of bias toward finding no association is that of an insensitive measuring tech- $\frac{\mathbb{D}}{3}$ nique. Clinical examination and nerve conduction:velocities may be normal early in the course of distal axonopathy. The most sensitive indicators of early axonopathy are sensory action potentials ${ }^{16}$ but these were measured and found to be normal.

Too few subjects can bias a study towards a nega-? tive effect. Although we did not have large numbers in our study, there was an $80 \%$ power to detect a $3 \mathrm{~m} / \mathrm{sec}$ difference between two groups at alpha equal to $5 \%$. A decrement of $3 \mathrm{~m} / \mathrm{sec}$ in nerve conduction velocity 0 may be clinically undetected because of the wide range N of normal values. ${ }^{17}$

One final consideration is the level of exposure to fluorocarbon experienced by our group of refrig- $\frac{\text { C }}{\Phi}$ eration repair workers which appears to be low. During repairs of large leaks exposure levels may be con- 0 
siderably higher and more data are needed to determine more precisely the current exposure levels in this group of workers. We conclude that at present exposure levels in the refrigeration repair trade fluorocarbons 12, 22, and 115 do not impair the peripheral nervous system.

We thank Ken Casey, Michael G Holthouser, Mark Passey, John Gardner, Sheran Smith, Virginia Aldrich, Mary Bishop, and Sara Shopkow for their help in this project.

\section{References}

${ }^{1}$ American Conference of Governmental Industrial Hygienists. Documentation of the threshold limit values for substances in workroom air. 3rd ed. Cincinnati: ACGIH, 1978.

${ }^{2}$ Herskowitz A, Ishii N, Schaumburg H. N-hexane neuropathy. $N$ Engl J Med 1971;285:82-4.

${ }^{3}$ Mendell JR, Saida K, Ganansia MF, et al. Toxic polyneuropathy produced by methyl n-butyl ketone. Science 1974;185:787.

${ }^{4}$ Sato K, Iwamasa T, Tsuru T, Takerechi T. An ultrastructural study of chronic cadmium chloride induced neuropathy. Acta Neuropathol 1978;41:185-90.

${ }^{5}$ Speizer FE, Doll $R$, Heaf $P$. Observations on recent increase in mortality from asthma. Br Med J 1968;i:335-9.
${ }^{6}$ Inman WHW, Adelstein AM. Rise and fall of asthma mortality in England and Wales in relation to use of pressurized aerosols. Lancet 1969;ii:279-85.

${ }^{7}$ Bass M. Sudden sniffing death. JAMA 1970;212:2075-9.

${ }^{8}$ Reinhardt CF, Azar A, Maxfield ME, Smith PE, Mullin LS. Cardiac arrhythmias and aerosol "sniffing." Arch Environ Health 1971;22:265-79.

${ }^{9}$ Speizer FE, Wegman DH, Ramirez A. Palpitation rates associated with fluorocarbon exposure in a hospital setting. $N$ Engl J Med 1975;292:624-6.

${ }^{10}$ Ferris BG. Recommended standardized procedures for pulmonary function testing. Am Rev Respir Dis 1978;118:55-88.

${ }^{11}$ Knudson RJ, Slatin RC, Lebowitz MD, Burrows B. The maximal expiratory flow-volume curve. Normal standards, variability and effects of age. Am Rev Respir Dis 1976;113:587-600.

${ }^{12}$ Azar A, Reinhardt CF, Maxfield ME, Smith PE, Mullin LS. Experimental human exposure to fluorocarbon 12 (Dichlorodifluoromethane). Am Ind Hyg Assoc J 1972;33:207-16.

${ }^{13}$ Stewart RD, Newton PE, Baretta ED, Hermann AA, Forster HV, Soto RJ. Physiological response to aerosol propellants. Environ Health Perspect 1978;26:275-85.

${ }^{14}$ Goldberg AD, Raftery EB, Cashman PMM. Ambulatory electrocardiographic records in patients with transient cerebral attacks or palpitation. $\mathrm{Br}$ Med J 1975;iv:569-71.

${ }^{15}$ McMichael AJ. Standardised mortality ratios and the "health worker effect": scratching beneath the surface. J Occup Med 1976;18:165-8.

${ }^{16}$ Le Quesne PM. Neurophysiological investigation of subclinical and minimal toxic neuropathies. Muscle Nerve 1978;1:392-5.

${ }^{17}$ Goodgold J, Eberstein A, eds. Electrodiagnosis of neuromuscular diseases. 2nd ed. Baltimore, MD: Williams and Wilkins Co, 1977.

\section{Destruction of manuscripts}

From 1 July 1985 articles submitted for publication will not be returned. Authors whose papers are rejected will be advised of the decision and the manuscripts will be kept under security for three months to deal with any inquiries and then destroyed. 